Aim of the study: Exposure to radiation and aging are the leading causes of breast cancer among female patients. We aimed to investigate and assess the relationship between exposure to medical, diagnostic and iatrogenic radiation and breast cancer using a questionnaire among 100 newly diagnosed female breast cancer patients and 100 control female subjects without cancer.

Material and methods: A case control study using a family ambulatory based survey was conducted among 200 female patients from all municipalities of Zenica-Doboj Canton. New cases of breast cancer among subjects of experimental groups $(n=100)$ were diagnosed between 1 January 2003 and 31 December 2007 using the institutional clinical procedure for breast cancer diagnosis. Data were obtained using a self-rated questionnaire on radiation as a breast carcinogen. Data analysis was performed using SPSS version 19.0.

Results: There were no significant differences between the two groups and their subgroups for individual data and demographics except for prevalence of decreased family financial situation (practical poverty) among subjects with breast cancer in relation to control subjects (31\%: $17 \%$ among control subjects; $p=0.001$ ). Female patients who are exposed to iatrogenic radiation before the $3^{\text {rd }}$ year of life $(\mathrm{OR}=1.29 ; 95 \% \mathrm{Cl}$ : 0.839-1.985) and those who are exposed to $\mathrm{CT}$ more than twice per year are more than twice as likely to have breast carcinoma $(\mathrm{OR}=2.02 ; 95 \% \mathrm{Cl}: 1.254-3.261)$ compared to control subjects. Poverty and low family income are vulnerability factors associated with elevated levels of breast carcinoma. This result is not in accordance with prior study results. Conclusions: It is necessary to develop an adequate registration system of iatrogenic exposure to radiation for each patient of any age, particularly for children aged $<3$ years and for $\mathrm{CT}$ iatrogenic exposure.

Key words: breast cancer risks, iatrogenic causes, medical radiation, ionized rays, X-rays, diagnostic computed tomography.

\section{Female breast cancer in relation to exposure to medical iatrogenic diagnostic radiation during life}

\author{
Ibrahim Gledoㅁ, Nurka Pranjic², Kenan Drljević ${ }^{3}$ Subhija Prasko, \\ Irdina Drljevic ${ }^{4}$, Piotr Brzeziński ${ }^{5}$ \\ 1Department of Family Medicine, Health Care Centre Zenica, Zenica, \\ Bosnia and Herzegovina \\ 2Department of Occupational Medicine, Tuzla University School of Medicine, \\ Tuzla, Bosnia and Herzegovina \\ ${ }^{3}$ Gynecology and Obstetrics Department, General Hospital "Prim. Dr. Abdulah Nakaš", \\ Sarajevo, Bosnia and Herzegovina \\ 4Dermatovenereology Department, Clinical Medical Centre, University of Sarajevo, \\ Sarajevo, Bosnia and Herzegovina \\ ${ }^{5}$ Dermatological Clinic, $6^{\text {th }}$ Military Support Unit, Ustka, Poland
}

\section{Introduction}

Nearly $50 \%$ of studies discovered breast cancer risk factors classified into categories as possible cancer risk factors. Only two of the risk factors are reliable and direct ones: ionizing radiation exposure and genetic damage. The beginning of breast cancer is usually a very long-lasting process; it can take carcinogens even 12 to 15 years to lead to carcinoma [1-5]. Ionizing radiation, diagnostic or therapeutic, increases the risk of breast cancer initiation, especially in younger women aged below forty [5]. Women in childhood and adolescence are far more sensitive to radiation than adult women. The risk is even higher if women have not given birth to a child yet. The dose of radiation is important and the risk grows within the received dose of the radiation. However, as far as mammography is concerned, with the implementation of modern technology the risk of diagnostic scanning every year at the age above forty is minimal [6]. Breast cancer incidence grows with women who were therapeutically irradiated for some other diseases, but also breast cancer increase is evident among the survivors of the radiation exposure of the atomic bombings in Japan [7]. The breast cancer incidence increase is evident 15-20 years after the exposure to radiation [8, 9]. Recent research showed that exposure to diagnostic radiography radiation is responsible for 29 breast cancer cases per year in women in the UK, aged up to 75, which is a small number compared to other western countries [10].

\section{Material and methods}

Survey methods

A case control study done by survey was conducted with the purpose of researching the connections between exposure to ionizing ( $\mathrm{X}$-ray) radiation during diagnosis (iatrogenic) and the development of newly discovered breast cancer in women treated at family health centers in the area of Zenica-Doboj Canton. This research encompassed 200 women, including 100 diagnosed with breast cancer according to clinical features (experimental group) and 100 examinees who have not been diagnosed with breast cancer or any other malignant diseases, but who underwent preventive ultrasonography examinations with general practitioners with the aim of prevention, early detection and screening of breast cancer (selected practitioners did ultrasonic breast examination along with clinical examination). Examinees from the experimental group were diagnosed with breast cancer in the period between 1 January 2003 and 31 Decem- 
ber 2007. The diagnosis was breast cancer (selected practitioners did ultrasonic breast examination along with clinical examination). The diagnosis was confirmed based on the clinical examination, ultrasonographic breast examination, mammography and histopathologically confirmed biopsy diagnosis or during the operative treatment 'ex tempora'.

\section{Sample of female respondents}

Selection of the examinees required the consent of an examinee to participate in the study, as well as on the breast cancer patient's general condition, which depended on the severity of the clinical features. Patients from the experimental group in the terminal phase of the disease, along with patients with benign breast tumors and clinically unsecured breast cancer diagnosis, were not included in the sampling. All examinees were classified according to age and occupation/working place, e.g. housewives, retired persons, teachers, health workers, administration workers, workers in manufacturing and those employed in the service industry. Housewives constituted the largest group, making up 52\% of women with breast cancer. Information on body mass index, employment/secure existence, wealth status and living place (countryside, city or an apartment close to industrial facilities) was also included in this research. We did not find any statistically significant difference between the examinees of the experimental and control groups $(p<0.05)$, nor the subgroups of the selected variables $(p<0.05)$, except for the wealth status variable $(p<0.001$; Table 1$)$. A significantly higher number of the examinees of the experimental group are in the category of poverty compared to the control subjects (31: 17; 31\%: 17\%; Table 1).

\section{Questionnaire items and measures}

The research was conducted according to the survey method, and the instrument of the research was a questionnaire specially designed for this research. The 'questionnaire on radiation exposure as a possible risk factor for

Table 1. Demographic and individual characteristics of the examinees compared among the groups

\begin{tabular}{|c|c|c|c|}
\hline & $\begin{array}{l}\text { Experimental group } \\
\qquad n=100(\%)\end{array}$ & $\begin{array}{l}\text { Control group } \\
n=100(\%)\end{array}$ & $p^{*}$ \\
\hline $\begin{array}{l}\text { Age groups (age) } \\
\qquad \begin{aligned} & 26-35 \\
& 36-45 \\
& >45\end{aligned}\end{array}$ & $\begin{array}{c}2(2) \\
15(15) \\
83(83)\end{array}$ & $\begin{array}{c}3(3) \\
18(18) \\
79(79)\end{array}$ & $0.451(z=0.75)$ \\
\hline $\begin{array}{l}\text { Occupation/working place } \\
\qquad \begin{array}{l}\text { Housewives } \\
\text { Retired persons } \\
\text { Teachers } \\
\text { Health workers } \\
\text { Administration workers } \\
\text { Workers in manufacturing } \\
\text { Industry service }\end{array}\end{array}$ & $\begin{array}{c}52(52) \\
24(24) \\
3(3) \\
2(2) \\
6(6) \\
4(4) \\
9(9)\end{array}$ & $\begin{array}{c}42(42) \\
17(17) \\
4(4) \\
18(18) \\
6(6) \\
6(6) \\
7(7)\end{array}$ & $0.147(z=1.45)$ \\
\hline $\begin{array}{l}\text { Body mass index (BMI) } \\
\qquad \begin{aligned} \text { Underweight } \\
\text { Ideal weight } \\
\text { Overweight } \\
\text { Obesity }\end{aligned}\end{array}$ & $\begin{array}{l}2(2) \\
27(27) \\
50(50) \\
21(21)\end{array}$ & $\begin{array}{c}4(4) \\
33(33) \\
43(43) \\
20(20)\end{array}$ & $0.425(z=0.80)$ \\
\hline $\begin{array}{l}\text { Employment/secure existence } \\
\qquad \begin{array}{l}\text { Unemployed } \\
\text { Employed } \\
\text { Pensions } \\
\text { Other source of income }\end{array}\end{array}$ & $\begin{array}{l}46(46) \\
15(15) \\
34(34) \\
5(5)\end{array}$ & $\begin{array}{l}35(35) \\
37(37) \\
26(26) \\
2(2)\end{array}$ & $0.817(z=0.23)$ \\
\hline $\begin{array}{l}\text { Wealth status } \\
\qquad \begin{array}{l}\text { The best } \\
\text { Much better than average } \\
\text { Better than average } \\
\text { Average } \\
\text { Below average } \\
\text { Much worse than average } \\
\text { Very difficult, suspense }\end{array}\end{array}$ & $\begin{array}{l}1(1) \\
0(0) \\
10(10) \\
58(58) \\
18(18) \\
6(6) \\
7(7)\end{array}$ & $\begin{array}{l}1(1) \\
2(2) \\
13(13) \\
68(68) \\
11(11) \\
2(2) \\
4(4)\end{array}$ & $0.001(z=2.99)$ \\
\hline $\begin{array}{l}\text { City } \\
\text { Countryside } \\
\text { Nearby industrial facilities }\end{array}$ & $\begin{array}{c}36(36) \\
58(58) \\
6(6)\end{array}$ & $\begin{array}{c}47(47) \\
46(46) \\
7(7)\end{array}$ & $0.730(z=0.35)$ \\
\hline
\end{tabular}


the genesis of breast cancer' came into existence based on the experience of evidence-based medicine. Before commencing the study, examinees were provided with necessary information about the aims and the purpose of the research. Filling in the questionnaire met the requirements for ethical anonymity. The questionnaire contains a group of questions about individual and demographic data (such as age, education, occupation, employment, address, assets and classification according to financial situation), and a group of questions on radiation exposure from early childhood, including iatrogenic diagnostic radiation. The second part of the questionnaire, related to exposure to iatrogenic diagnostic radiation, addressed the following variables: exposure to $X$-ray radiation before the third year of life (possible answers: no, I don't know, yes); history of frequency of exposure to $X$ ray radiation during the life time (possible answers: once in five years, once in two years, once in one year, several times a year); frequency of exposure to radiation during computed tomography (CT scan; possible answers: never, once a year, twice a year, several times a year); as well as the history of frequency of radiation during diagnostic procedures with nuclear medicine (never, once a year, twice a year, several times a year). The exposure to radiation of the affected people was analyzed, as well as the well-known class A carcinogens and their association with the genesis of breast cancer.

\section{Data analysis}

For the statistical analysis, standard methods of descriptive statistics were used (central tendency measures and dispersion measures). In favor of testing differences of statistical significance, among the samples parametric and non-parametric significance tests were used ( $\chi^{2}$ test, MannWhitney z-test). For linear correlation analysis a Tukey test was used (ANOVA). However, for multivariate correlation analysis we used ANOVA (logistic regression analysis). Breast cancer was a dependent variable. Multivariate regression analysis for which the characteristics of diagnostic exposure to ionizing, X-ray radiation was a potential independent carcinogen predictor, but modified variables (potential retrograde factors) were age, occupation/working place, BMI, employment, wealth status and living place. All variables which were used in logistic regression analysis were divided into two different groups. The odds ratio (OR; statistically significant OR $>1.0$ ) and $95 \%$ confidence interval were calculated. Statistical hypotheses were tested at the significance level $p<0.05$. Data analysis was performed using SPSS version 19.0.

\section{Results}

The highest number of examinees was in the age group above 45 years in both groups, the experimental one with $83 \%$ of breast cancer and $79 \%$ in the control group without cancer. There were no significant differences in the distribution of the examinees according to the age and the groupings $(z=0.75 ; P=0.451)$. According to our samples, housewives, $52 \%$ of them, most often are affected by breast cancer, retired women are second with $24 \%$, and among employed women, those from the service industry are third. There is no significant difference according to occupation among the groups $(z=1.45 ; P=0.147)$. Examinees who were in the exper- imental group and diagnosed with breast cancer, according to their financial situation, mostly belong to the subgroups with average income (58\%) and lower than average: below the average were $18 \%$ of examinees, much lower than the average $6 \%$, and far below the average $7 \%(=30 \%)$. We can say that in the subgroups of the poor there were $31 \%$ of examinees compared to $17 \%$ from the control group (31\% vs. $17 \%$; $P<0.001$; Table 1). Poverty is identified as a risk for breast cancer development. The risk factors for breast cancer development include the living standard, poor financial situation and dissatisfaction with it, as they constantly cause stress in our examinees.

Ten examinees of the control and experimental group were exposed to $X$-ray radiation before the age of three. Frequency of $X$-ray exposure before the age of three was equally represented in both groups ( $10 \%$ vs. $10 \% ; z=0.245 ; P=1.160$ ); there is no statistically significant difference between the groups. Examinees affected with breast cancer were more frequently exposed to $X$-ray radiation during the CT scan: once a year in the group affected by breast cancer (22\% vs. 11\%); twice a year ( $6 \%$ vs. $3 \%$ ) and several times a year ( $6 \%$ vs. $1 \%$ ). There is a statistically significant difference between the groups in exposure to CT scanning $(z=2.89$; $P=0.004)$ : They were exposed to $X$-ray radiation more frequently during the conduction of procedures in nuclear medicine; once a year in the group affected by breast cancer (24\% vs. $19 \%$ ); twice a year (4\% vs. $3 \%$ ) and several times a year were exposed equally, but we have not discovered a significant difference between the groups; $z=0.872 ; P=0.16$ (Table 2).

A predictor of breast cancer development connected to exposure to $X$-ray radiation for diagnostic purposes is the CT diagnostic scan twice or several times a year $(p=0.001$; Tukey F-test; Table 3).

A risk factor for breast cancer development in relation to exposure to $X$-ray radiation for diagnostic purposes is the $\mathrm{CT}$ scan conducted twice or several times a year $(P=0.002)$.

Statistically significant risk factors for the genesis of breast cancer from iatrogenic radiation included exposure to $X$-ray radiation before the age of three $(\mathrm{OR}=1.2908$; $95 \% \mathrm{Cl}$ : $0.839-$ 1.985), and exposure to CT diagnostics twice or several times $(\mathrm{OR}=2.022 ; 95 \% \mathrm{Cl}: 1.254-3.261)$. The retrograde factor is age, with the risk increased with aging - above 45 years of life.

\section{Discussion}

Breast cancer is more than 100 times more common in women than in men. The practice in developed countries can explain factors for the genesis of breast cancer, which are connected to exposure to estrogens during the reproductive period or changes in the concentration of this hormone with obese people, alcohol consumers and persons with less physical activities $[1-4,15,16]$. The biggest risk factor, besides sex, is age. The older a person is, the greater is the risk of getting this malignancy $[3,5]$. This conclusion is proven with our results. Women older than 45 have approximately 1.3 -fold higher risk of being affected with breast cancer, as result of aging. Zenica-Doboj Canton is an area in the central part of Bosnia and Herzegovina with an area of $3343.3 \mathrm{~km}^{2}$. The population is 400,601 (119.8 people per $\mathrm{km}^{2}$ ). This area is 
Table 2. Distribution of all examinees according to the frequency of X-ray exposure during radiography and CT scan

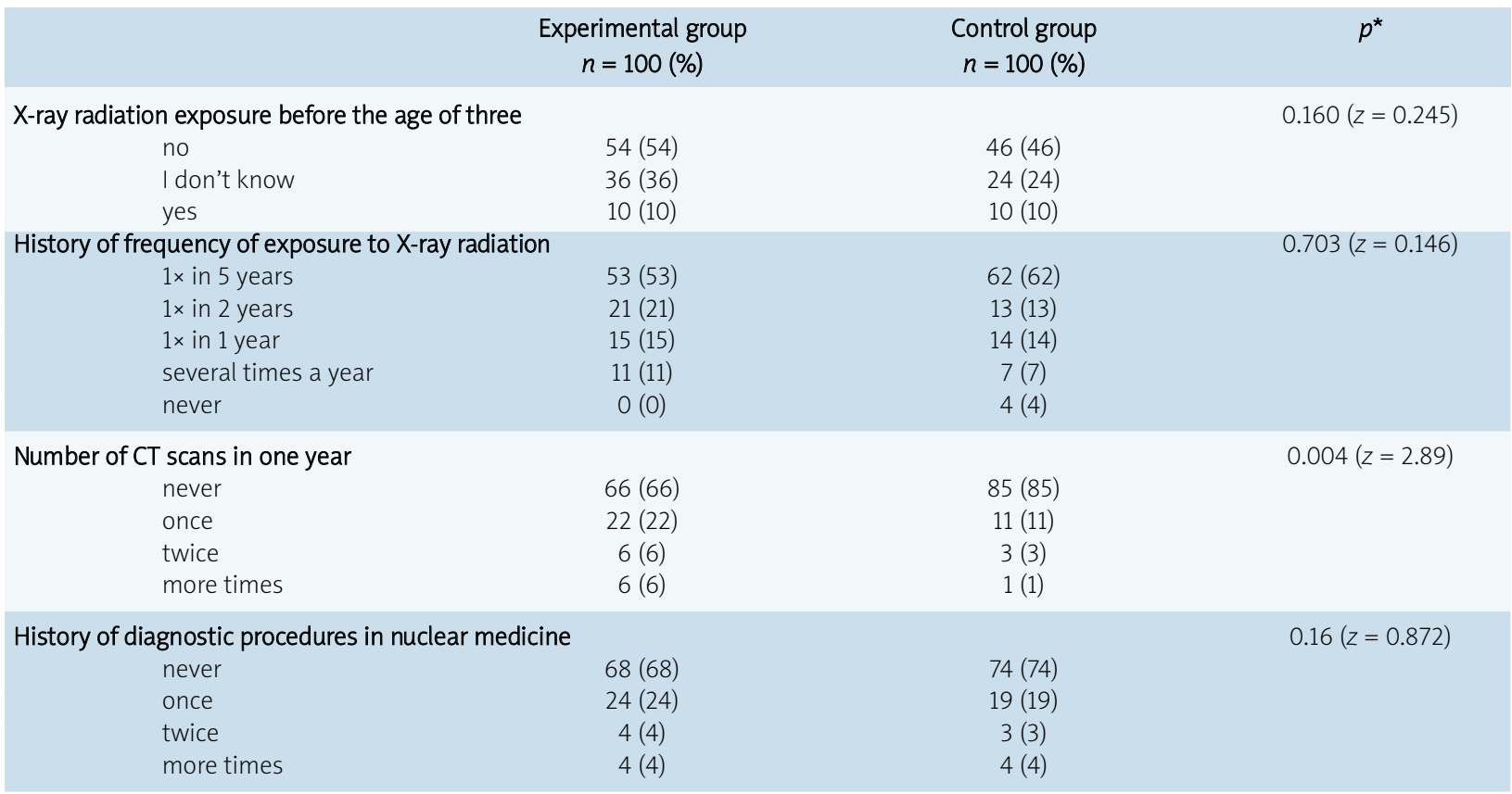

*Mann-Whitney test

Table 3. Distribution of identified risk factors for the development of breast cancer in the experimental group who were subjected to $\mathrm{X}$-ray exposure for diagnostic purposes according to their presence/ absence obtained by self-response

\begin{tabular}{|c|c|c|}
\hline Risk factors & $\mathrm{F}$ & $P^{\star}$ \\
\hline exposure to $\mathrm{X}$-ray radiation before the age of three & 1.597 & 0.208 \\
\hline exposure to X-ray diagnostic scan & 0.146 & 0.703 \\
\hline exposure to computed tomography & 10.041 & 0.002 \\
\hline $\begin{array}{l}\text { exposure to diagnostic procedures of nuclear } \\
\text { medicine }\end{array}$ & 0.441 & 0.507 \\
\hline
\end{tabular}

*Tukey's F-test (ANOVA)

a cantonal unit of the Federation of Bosnia and Herzegovina (FB\&H). In 2009 in FB\&H breast cancer made up 74.5\% of all registered malignant diseases in women (structure index $26.1 \%$ ) and is the main cause of mortality [17]. In our sample of 100 patients with recently discovered breast cancer, two out of 100 examinees (2\%) were in the 26-35 age group, 15 in the 36-45 age group, and the biggest number were above 45 years of age, 83 of them (83\%). In the USA in the period 2000-2004 the average age for establishing a breast cancer diagnosis was 61 years. Breast cancer was not diagnosed in women younger than $20 ; 1.9 \%$ of them were aged 20-34, 10.6\% aged $35-44,22.2 \%$ aged $45-54,22.9 \%$ aged $55-64,20.2 \%$ aged $65-74,16.7 \%$ aged $75-84$ and $5.4 \%$ above 85 years of age [11]. Results are similar for other countries; e.g. in the UK, according to the data of the National Cancer Center in 1996, the risk for breast cancer development at the age of 25 is one in 15,000 women, up to the age of 30 one case in 1,900 women, up to the age of 40 also one case in 200 women, up to the age of 50 one case per 50 women, up to 60 years of age one case in 23 women, up to the age of 70 one woman in 15, up to the age of 80 one woman in 11 , up to the age of 85 one case per 10 women $[10,18]$. Our results show higher frequency of breast cancer at a younger age in developed countries.

Ionizing radiation is a confirmed risk factor for breast cancer [6]. According to the results of the previously conducted research, exposure to $X$-ray radiation after 40 years of life has a decreasing trend, but exposure to radiation before the age of 20 significantly affects the genesis of breast cancer because the child's cells and younger person's cells are more sensitive to radiation. The risk increases because of the radiation accumulation; thus a person exposed to ionizing radiation (more often $\mathrm{X}$-ray radiation) for a period longer than 1015 years is at higher risk. The risk of getting breast cancer after the exposure persists during further life time because of the accumulated dosage of radiation. A previously conducted study has also discovered that there is a growing risk of breast cancer for women who were receiving high doses of ionizing radiation (<100-200 cGy). Meanwhile, the risk is statistically significant in younger women who were exposed to smaller doses in childhood and youth before 20 years of age (OR $=1.4,95 \%$ $\mathrm{Cl}, 1.2-1.8)[3,11,19-22]$. The research showed 12 to 25 times higher frequency of breast cancer in women who were radiated for Hodgkin's lymphoma treatment up to 30 years of age [19]. Radiotherapy is connected to the risk of cancer of the other breast and has a growing trend for decreasing patient's age after the first treatment (age $<35, \mathrm{OR}=1.78,95 \% \mathrm{Cl}, 0.85$ to 3.72; age $<45, \mathrm{OR}=1.09,95 \% \mathrm{Cl}, 0.82$ for 1.45 ) [21-23]. Our research is in agreement with the results of other authors. However, may it be assumed that the incidence numbers of newly discovered breast cancers in the younger generation in FB\&H are after all a result of bad supervision of the prob- 
lem of exposure to radiation during childhood and youth for diagnostic purposes by public health services? There is a trend of conducting CT scans of nasal sinuses upon the recommendation of otolaryngologists (in $99 \%$ of cases the test does not reveal a chronic inflammatory process - noted from practical experience).

According to published studies women of high social status are at higher risk of getting a breast cancer [24-27]. Our results are opposite to this statement and indicate that poverty and bad economic situation of the family, along with dissatisfaction with the mentioned situation, pose a significant risk factor for the genesis of breast cancer. Perhaps, in both cases, the main reason is the level of stress. According to the results of previous research, exposure to $X$-ray radiation after 40 years of age does not significantly influence the genesis of breast cancer $(p=0.18)$, but exposure to radiation before 20 years of age significantly influences the initiation of breast carcinoma [28]. On the other hand, the risk rises because of radiation accumulation (frequency of iatrogenic exposure to $X$-ray radiation), so a person exposed to ionizing radiation at the age of $10-15$ is at higher risk. Therefore, we are talking about the length of the exposure that increases with the frequency of the exposure and the dosage of radiation which are at the highest intensity during the CT scan. The breast cancer risk after exposure to radiation persists within the body during the life time [29,30]. The research dealing with the influence of small doses of radiation on the breast cancer risks in women with positive family history and benign changes of the breasts showed that there is a significant increase of the risk with the exposure to small radiation doses in women younger than 20 [2]. Our research also showed that exposure to diagnostic radiation before the age of three $(O R=1.29)$ is identified as a risk factor. However, the results of our research showed that breast cancer development is increased twice as much with exposure to CT diagnostic procedures (< twice a year). It seems that breasts are more sensitive to radiation at a younger age, which is in accordance with the theory that the final phase of the development of milk ducts happens during pregnancy and lactation increases the resistance to cancer [25].

This study is accompanied by certain difficulties and limitations. The basic limitation is the relatively small number of subjects. Another important limitation of this study is the deficiency in the registration of characteristics of exposure, duration of radiation in relation to age subgroups and intensity of dose of exposure to radiation in assessment of breast carcinogen risks (for example, various exposure doses in case of CT diagnostics of various parts of the body).

In conclusion the study results suggest and confirm prior knowledge that exposure to medical radiation for diagnostic purposes represents a risk factor for breast carcinoma. Although the radiation from lung radiography or other parts of the body among children aged $<3$ years is a low dose, the cumulative effect can cause cancer during the long-term latency period. Age is statistically an important breast cancer risk, but increased age decreased breast cancer risk and was not statistically significant [1-6]. The exception was exposure more than 2 times to radiation and commutation of expo- sure particularly in the case of CT diagnostic procedures. It could be prevented by selective exposure to ionized rays of patients in strictly indicated cases. It is necessary to use other less damaging diagnostic methods to achieve a significant decrease of radiation dosage risk in strictly indicated diagnostic cases [31].

Based on the results of this study it is necessary to conduct education about risk factors for breast carcinoma, damage of medical radiation, particularly radiation during $\mathrm{CT}$ diagnostics, and to create a register for all patients who were exposed to diagnostic radiation including the following data on the exposure: when, where, how, how much, why.

\section{Footnotes}

We hereby confirm that the procedures involving experiments on human subjects were done in accordance with the ethical standards of the Committee on Human Experimentation of the institution in which the experiments were done or in accordance with the Helsinki Declaration of 1975.

The authors declare no conflict of interest.

\section{References}

1. Brody JG, Rudel RA. Environmental pollutants and breast cancer. Environ Health Perspect 2003; 111: 1007-19.

2. Hill DA, Preston-Martin S, Ross RK, Bernstein L. Medical radiation, family history of cancer, and benign breast disease in relation to breast cancer risk in young women, USA. Cancer Causes Control 2002; 13: 711-8.

3. Byrne C. Mammographic density: a breast cancer risk factor or diagnostic indicator? Acad Radiol 2002; 9: 253-5.

4. Mattsson A, Rudén BI, Hall P, Wilking N, Rutqvist LE. Radiationinduced breast cancer: long term follow-up of radiation therapy for benign breast disease. J Natl Cancer Inst 1993; 85: 1679-85.

5. Laniauskaitė I, Ožalinskaitė A, Strupaitė R, Bylaite M. Skin cancer knowledge, attitude and behavior towards sun exposure among young adults in Lithuania. Our Dermatol Online 2011; 4: 189-95.

6 Ronckers CM, Erdmann CA, Land CE. Radiation and breast cancer: a review of current evidence. Breast Cancer Res 2005; 7: 21-32.

7. Tokunaga M, Land CE, Yamamoto T, Asano M, Tokuoka S, Ezaki H, Nishimori I. Incidence of female breast cancer among atomic bomb survivors, Hiroshima and Nagasaki, 1950-1980. Radiat Res 1987; 112: 243-72.

8. Vinh-Hung V, Burzykowski T, Van de Steene J, Storme G, Soete G. Post-surgery radiation in early breast cancer: survival analysis of registry data. Radiother Oncol 2002; 64: 281-90.

9. Schnitt SJ, Connolly JL, Harris JR, Hellman S, Cohen RB. Pathologic predictors of early local recurrence in stage I and II breast cancer treated by primary radiation therapy. Cancer 1984; 53: 1049-57.

10. Berrington de González A, Darby S. Risk of cancer from diagnostic X-rays: estimates for the UK and 14 other countries. Lancet 2004; 363: 345-51.

11. U.S. Department of Health and Human Services, Breast Cancer Screening. Accessed online at www.ahrq.gov/clinic/uspstf/uspsbrca.htm, on Nov. 20, 2009

12. John EM, Kelsey JL. Radiation and other environmental exposures and breast cancer. Epidemiol Rev 1993; 15: 157-62.

13. Snedeker SM, Diaugustine RP. Hormonal and environmental factors affecting cell proliferation and neoplasia in the mammary gland. Prog Clin Biol Res 1996; 394: 211-53.

14. Easton DF. Familial risks of breast cancer. Breast Cancer Res 2002; 4: 179-81. 
15. Key TJ, Appleby PN, Reeves GK, et al. Body mass index, serum sex hormones, and breast cancer risk in postmenopausal women. J Natl Cancer Inst 2003; 95: 1218-26.

16. Chang SC, Ziegler RG, Dunn B, et al. Association of energy intake and energy balance with postmenopausal breast cancer in the prostate, lung, colorectal, and ovarian cancer screening trial. Cancer Epidemiol Biomarkers Prev 2006; 15: 334-41.

17. Institute for public health FB\&H. Health Epidemiological Situation in FB\&H in 2010: epidemiological bilten. Sarajevo-Mostar, 2011.

18. Office for National Statistics. Cancer statistics registration of cancer diagnosed in 2008, England. Series MBI, no. 39. National Statistics, London 2010.

19. Guibout C, Adjadj E, Rubino C, et al. Malignant breast tumors after radiotherapy for a first cancer during childhood. J Clin Oncol 2006; 23: 197-204.

20. Stewart LA, Parmar MK. Meta-analysis of the literature or of individual patient data: is there a difference? Lancet 1993; 341: 418-22.

21. De Bruin ML, Sparidans J, van't Veer MB, et al. Breast cancer risk in female survivors of Hodgkin's lymphoma: lower risk after smaller radiation volumes. J Clin Oncol 2009; 10: 4239-46.

22. Gao X, Fisher SG, Emami B. Risk of second primary cancer in the contra lateral breast in women treated for early-stage breast cancer: a pop ulation based study. Int J Radiat Oncol Phys 2003; 56: 1038-45.

23. Hooning MJ, Aleman BM, Hauptmann M, et al. Roles of radiotherapy and chemotherapy in the development of contralateral breast cancer. J Clin Oncol 2008; 26: 5561-8.

24. Overgaard $M$, Jensen MB, Overgaard J, et al. Postoperative radio therapy in high-risk postmenopausal breast-cancer patients given adjuvant tamoxifen: Danish Breast Cancer Cooperative Group DBCG 82c randomized trial. Lancet 1999; 353: 1641-8.

25. Fenton SE. Endocrine-disrupting compounds and mammary gland development: early exposure and later life consequences. Endocrinology 2006; 147: S18-24.

26. Pukkala E, Weiderpass E. Time trends in socio-economic differences in incidence rates of cancers of the breast and female genital organs (Finland, 1971-1995). Int J Cancer 1999; 81: 56-61.

27. Hemminki K, Li X. University and medical education and the risk of cancer in Sweden. Eur J Cancer Prev 2004; 13: 199-205.

28. Tokunaga M, Land CE, Tokuoka S, Nishimori I, Soda M, Akiba S. Incidence of female breast cancer among atomic bomb survivors, 19501985. Radiat Res 1994; 138: 209-23.

29. Shaham J, Gurvich R, Goral A, Czerniak A. The risk of breast cancer in relation to health habits and occupational exposure. Am J Ind Med 2006; 49: 1021-30.

30. Pranjić N, Karamehić J, Ljuca F, Zigić Z, Ascerić M. Internal contamination with depleted uranium and health disorders. Med Arh 2002; 56: 39-42.

31. Dedić S, Pranjić N. Lung cancer risk from exposure to diagnosti X-rays. Health Med 2009; 3: 307-13.

\section{Address for correspondence}

Ibrahim Gledo, MD, MS

Department of Family Medicine

Health Care Medical School, University of Zenica

72000 Zenica, Bosnia and Herzegovina

e-mail: anida1@bih.net.ba

Submitted: $\quad 2.07 .2012$

Accepted: $\quad 2.08 .2012$ 